Journal of Social Research and Behavioral Sciences

OriginalArticle

Received/Accepted Dates

05.11.2021/21.12.2021

Sosyal Araştırmalar ve Davranış Bilimleri Dergisi

DOI:10.52096/jsrbs.7.14.11

ISSN:2149-178X

Volume: 7 Issue: 14 Year: 2021

\title{
Fenomen Annelerin Fenomen Pazarlaması Kapsamında Yaptıkları Paylaşımlar Üzerine Bir Íçerik Analizi ${ }^{1}$
}

\author{
Dr. Yeliz Yapıcıŏglu Ayaz \\ yeliz.yapicioglu@gmail.com \\ Doç. Dr. Pınar Aytekin ${ }^{3}$ \\ pinar.aytekin@idu.edu.tr
}

\section{Özet}

Dijitalleşmenin gelişmesiyle birlikte yaşam içerisindeki tüm alanlar bu gelişmeye ayak uydurmaya başlamıştır. Bu alanlardan bir tanesi de pazarlamadır. Geleneksel yöntemlerin dijital dünyaya adapte edilmeye çalışılması sürecinde pazarlamacılar için farklı arayışlar söz konusu olmuş ve pazarlama teknikleri bu doğrultuda tekrardan formüle edilmeye başlanmıştır. Bu kapsamda, dijital dünyanın yeni iletişim kanalları sunması pazarlamacıların tüketicilerle olan ilişkilerini farklı boyutlara taşımıştır. Firmalar artık Facebook, Twitter, Youtube, Instagram gibi sosyal medya kanallarını pazarlama aracı olarak kullanmaya başlamışlardır. Bu ortamlar ayrıca fenomen pazarlamasının doğmasında da etkili olmuştur.

Amaç: Araştırma, fenomen annelerin Instagram hesaplarında ürünler ve markalar ile ilgili paylaşımlarını derinlemesine ele alma amacını taşımaktadır.

Yöntem: Takipçi sayıları baz alınarak ele alınan 14 annenin hesapları ürün ve marka çerçevesinde biçimlendirilmiş 10 kategori doğrultusunda içerik analizi ile incelenmiştir.

Bulgular: İçerik analizi kapsamında, takipçi sayıları yüksek olan 14 fenomen annenin ürün/marka içerikli paylaşımlarındaki paylaşım adetleri, yoğunlukları, paylaşım zamanları, paylaşımlardaki yorumlar ve paylaşımlardaki içeriklerde nelerin yer aldığı gibi konularda genel çerçeve çizilmeye çalışarak hesaplar arasındaki farklılıklar ve benzer yönler sayısal olarak değerlendirilmeye alınmıştır.

${ }^{1} \mathrm{Bu}$ çalışma 29-31 Ekim 2021 tarihleri arasında Antalya'da düzenlenen 10. Uluslararası Sosyal Araştırmalar ve Davranış Bilimleri Sempozyumu'nda sunulan "Fenomen Pazarlaması: Fenomen Anneler Üzerine Bir İçerik Analizi" başlıklı bildirinin genişletilmiş halidir.

${ }^{2}$ Ege Üniversitesi, İletişim Fakültesi, Reklamc1lık Bölümü, ORCID: 0000-0002-4488-9759.

${ }^{3}$ İzmir Demokrasi Üniversitesi, İktisadi ve İdari Bilimler Fakültesi, İşletme Bölümü, ORCID: 0000-0003-4313-1927. 
Özgünlük: Özellikle son yıllarda sosyal medya mecrası olan ön plana çıkan İnstagram yoluyla çok sayıda birey fenomenlik kazanmaya çalışarak markalar ile işbirliği içerisine girip reklamlarını yaparak sahip oldukları takipçileri ve kendilerini takip eden kitleleri yönlendirmeye başlamışlardır. Markalar için fenomen kişiler tüketici grupları ile köprü görevini gören elçiler ön planda olan bireyler haline gelmektedirler. Bu kapsamda, fenomen pazarlama ile ilgili araştırmalara ihtiyaç duyulmaya başlanmıştır. Çalışma, ürün ve marka etkileşimiyle tüketici grupları ile aktif iletişimde olan fenomen anneler konusunda literatüre katkı sağlama konusunda özgün bir özellik taşımaktadır.

Anahtar Kelimeler: Fenomen Pazarlama, Fenomen Anneler, Reklam, Sosyal Medya, Instagram, İçerik Analizi Jel Sınıflandırması:M31,M37

\title{
A Content Analysis on Phenomenon Moms' Sharings within the Scope of Influencer Marketing
}

\begin{abstract}
All areas of life have been started to keep in step with developments according to improvements of djitilization. One of the areas which develop according to dijitilization is marketing. Marketers find out different things with the process of traditional methods to dijital world and marketing techniques have been began to reformulate. In this context, relationships of marketers and consumers transmit to other size. Social media tools like Facebook, Twitter, Youtube and Instagram are used as a new marketing tool. Influencer marketing has been developed in compliance with these new social media platforms.
\end{abstract}

Purpose: The purpose of study to take hand Instagram accounts of influencer moms deeply with regard to their sharings about products and brands.

Methodology: Accounts of influencer moms was investigated according to their follower numbers and their sharings was analyzed with formalized ten categories through content analysis.

Findings: Numbers of followers of these mothers accounts' are higher and their sharings were evaluated dissimilarities and similarities according to sharing numbers, intensity, sharing times of contents, comments about sharings, and which things take place in sharing contents

Orijinality: Particularly, Instagram, has came into prominence as a social media tool in recent years. Many people who try to become influencer and cooperate with brands. They manipulate their followers to buy brands. They are like a bridge between brands and consumer groups.In this context, it is needed researchers about influencer marketing.This study provide contribution about influencer moms who are effecitve communication with consumer groups about products and brands and this study has the characteristics from this point of view.

Key Words: Influencer Marketing, Influencer Mom, Advertising, Social Media, Instagram, Content Analysis Jel Classification:M31,M37 


\section{Giriş}

Günümüzde internetin yaygınlaşması ve ulaşılabilir olması sayesinde, ağızdan ağıza iletişim elektronik ortama adapte olmuş ve eski kavramlar yeniden yorumlanmaya başlamıştır. Bu yeni yorumlamalar ise hayatımıza yeni kavramlar getirmiş̧tir (Can ve Koz, 2018:447). Yeni dünya düzeninde dijitalleşmenin etkisi ile birlikte iletişim biçimleri artık farklı kanallar üzerinden gerçekleştirilmektedir. Pazarlamacılar, ürünlerin ve markaların tanıtımında bu kanallardan biri olarak; tanınırlığı ve bilinirliği yüksek olan bireyleri kullanmaya ve bu kişilerle tüketiciler arasında köprü kurmaya başlamıştır. Bu kişiler ünlü olsun veya olmasın fenomen olarak isimlendirilmektedirler. Fenomen isminin literatürde farklı isimlerde de yer aldığı̆ görülmektedir. Influencer şeklinde de kullanılan bu kavram, sosyal medya platformlarından birinde güçlü bir izleyici kitlesine sahip olan ve içerik ürettiği alanda düşüncelerine önem verilen kişi anlamına gelmektedir (Sevinç, 2018).

Fenomenler, farklı platformlar ve iletişim kanalları kullanarak klasik medyada görülen tek yönlü iletişimi çift yönlü iletişime döndürebilmektedirler. Bu sebeple takipçileriyle daha güçlü bir iletişime sahiptirler. $\mathrm{Bu}$ durum etki düzeyinin klasik medya ile tanınan kişilere göre daha fazla olmasını sağlamaktadır (Pektaş ve Ormanlı, 2019:1402). Karşılıklı soru cevap ya da yorum yapma şeklinde olabilen bu iletişim şekli, iki tarafın daha çok etkileşim halinde olabilmesini sağlayabilmektedir.

Çok sayıda kullanıcı fenomenleri sosyal ağlar üzerinden takip edebilmekte, fenomenler de sayfalarında pek çok ürün ve hizmet paylaşımında bulunarak takipçilerini etkileyebilmektedirler. $\mathrm{Bu}$ nedenle fenomenler reklam verenlerin reklam sürecinde yararlanabilecekleri bir faktör olarak görülmektedir (Aslan ve Ünlü, 2016: 44). Bu doğrultuda, sosyal platformlarda ön plana çıkan ve tüketici grupları ile ilişkileri biçimlendiren ve etkileşim sağlayan bu kişiler pazarlama literatürüne "fenomen (influencer) pazarlaması" kavramının girmesinde etkin rol oynamışlardır. Sosyal medya kullanımının hızla artmasıyla birlikte ortaya çıkan bu yeni pazarlama tekniği, çevrimiçi bağlantı kanalları yoluyla yeni fikir ve ürünlerin daha fazla tüketiciye ulaşma şansını arttırmaktadır. Fenomen pazarlaması; sosyal medyada yüksek sayıda takipçi sayısına sahip kişiler aracılığıyla, 
şirketlerin ürün ve hizmetlerini tanıtabilecekleri, yeni iletişim modelleri geliştirebilecekleri bir mecra olarak büyümeye devam etmektedir (Baker, 2014). Tavsiyeye dayalı bir sistem üzerinden yürümekte olan bu teknikte, çeşitli ürün ve hizmetler sosyal medyada fenomenler tarafindan tanıtılmakta ve takipçiler bu ürün ve hizmetleri kullanmaya teşvik edilmeye çalışılmaktadır. $\mathrm{Bu}$ çalışmada; öncelikle fenomen pazarlaması kavramından bahsedilmiş, daha sonra sosyal medya platformu olan Instagram'da fenomen annelerin yaptıkları paylaşımlar, çeşitli kategoriler doğrultusunda içerik analizine tabi tutulmuş ve yapılan bu analizler sonucu elde edilen bulgular değerlendirilmiştir.

\section{Fenomen Pazarlaması Kavramına İlişskin Literatür}

Fenomen pazarlamasının ortaya çıkışı 2000'li yıllara dayanmaktadır. 2000'li yıllarda fenomen adı verilen tanınırlı̆ğ ve bilinirliği yüksek olan bireyler kendi açtıkları bloglar aracılığı ile çeşitli kitleler ile iletişim kurmaya ve bloglarında işledikleri konular kapsamında belirli bir kitle elde etmeye başlamışlardır. Dijitalleşme sürecinde, pazarlamacıların belirli bir marka veya ürünün reklamını yapmaları için bu kişilere ödeme yapmak üzere bütçe ayırmaları ile pazarlama dünyasında farklı bir dönemin kapıları açılmıştır. Tanınırlık ve bilinirliğin dışında dijital dünyada yeni olan iletişim kanallarından Facebook, Twitter, Youtube ve Instagram gibi kanallar ile pek çok kişiye ulaşılması ile birlikte ürünlerin ve markaların reklamlarının farklı bir biçimde yapılmaya başlanmasının da temelleri atılmıştır. Pazarlamacılar reklam stratejilerinden kazanç elde etmek için bu yeni kitle iletişim kanallarını araştırmaya başlamışlardır (Tabellion ve Esch, 2019:1).

İnternete olan erişim, sosyal ağların varlığı ve mobil iletişim (Trusov vd., 2009); çeşitli ve çok sayıda temsilci, diğer bir ismi ile fenomen tarafından ağızdan ağıza iletişimin etkisinin artmasını sağlamıştır (Brown ve Hayes, 2008). Fenomen pazarlamasının bulunduğu yerde ağızdan ağıza pazarlama söz konusudur ve kontekste karşı yapılan eylemler daha başarılı bir şekilde yürütülmektedir (Sudha ve Sheena, 2017). Fenomenler, sosyal medyada ağızdan ağıza iletişim konusunda etkili olabilecek tüketicilere odaklanarak, büyük tüketici gruplarına ulaşabilmektedirler (Duan ve Whinstion, 2008: 1007-1016). Yüksek takipçi sayılarına sahip fenomenler bu konuda çok daha başarılı olabilmekte, ağızdan ağıza iletişimin de etkisiyle geniş kitlelere ulaşabilmeleri mümkün olabilmektedir. 
Sosyal medya tüketiciler ve markalar arasındaki güç dengesini temelden değiştirmiştir, çünkü satın alma kararlarında belirli bir unvana sahip kişilerin tavsiyeleri önemli rol oynamaktadır (Wong, 2014). Fenomen pazarlaması, yukarıda da belirtildiği gibi, temelde ağızdan ağıza pazarlamanın bir biçimidir. Bughin vd., (2010) çalışmalarında, ağızdan ağıza pazarlamanın satışları ücretli reklamlara oranla ikiye katladığını ve tüketicilerin hatırlama oranlarının \%37 daha yüksek olduğunu belirtmişlerdir. Fenomen pazarlaması, çevrimiçi bir pazarlama yöntemi olduğundan dolayı, pazarlamacılar için yeni ve sıcak bir gündem alanı oluşturmuştur (Brown ve Hayes, 2015:7). Facebook, Youtube ve Instagram gibi sosyal medya kanalları sağladıkları etkileşim ve yoğun kullanıcı sayılarıyla tüketici iletişiminde birçok firmanın bütünleyici birer parçası olmaktadır (Schulten vd., 2012:3). Çünkü pazarlamacılar, daha düşük maliyetlerle, kullanıcı sayısı çok yüksek olan bu kanallar aracıllğıyla ve ağızdan ağıza iletişimin de etkisiyle çok büyük kitlelere ulaşabilmektedirler.

Fenomen pazarlaması; bir pazarlama yöntemi olarak, firmaların seçtikleri fenomenlere, kendi markalarına yönelik içerik yaratmaları veya ürün ya da markayı takipçilerine tanıtmaları amacıyla yatırım yapmalarını ifade etmektedir (Yodel, 2017). Fenomen pazarlaması, sosyal medya üzerinden fenomenlerin kullanılarak geniş pazarlarda marka mesajlarının yürütülmesi olarak da tanımlanabilir (Tapinfluence, 2017). Fenomen pazarlaması gittikçe popüler hale gelmektedir ve firmalar sosyal medya fenomenleri ile bu fenomenlerin sosyal medya profilleri üzerinden ürünlerinin tanıtımını yapmaları için çeşitli şekillerde antlaşmaktadır (De Veirman vd., 2017).

Fenomenler sosyal medya kullanıcısı olarak ünlü kişilere göre daha az bilinmekte ve daha az popüler olmalarına rağmen etkinliklerini sürdürmektedirler. Onlar bir çeşit kanaat liderleridir, fakat ünlüler ve normal insanlar gibi de değillerdir (Brown ve Hayes, 2015). Sudha ve Sheena'ya (2017) göre fenomen pazarlaması; tanımlamak ya da ifade etmek için etiketleme yapılması ve belirli bir kalabalığın belirli bir etki ile elde tutulmasıdır. Fenomen pazarlamasında; fenomenler tüketiciler ile doğrudan ve organik bir şekilde iletişim kurarak, markaları kendi yaşamları içerisinde göstermekte ve ortalama bir tüketicinin kendisi için bir şeyler bulabileceği şekilde desteklemektedirler (Tabellion ve Esch, 2019). Bazen sabah kahvaltısını hazırlarken belli bir markaya ait mutfak aletinin ne kadar pratik olduğunu anlatabilmekte, bazen de dışarı çıkmadan önce yaptığı makyaj esnasında bir allık, fondöten ya da ruj markasını kullanırken göstererek tanitabilmektedirler. 
Sosyal medya firmaların insanlar ile bağlantı kurmasında yeni firsatlar sunmaktadır. Sosyal medya platformları sayesinde yeni topluluklara ulaşmak, fenomenler aracıllğıyla kurulan güvenilir ilişkilerle tüketiciyi marka veya ürüne bağlamak mümkün olabilmektedir (Vodak vd., 2019:212). Fenomenler marka ve ürüne karşı doğal bir ilgi yaratmakta, tüketicilerle işbirliği sağlamaktadırlar, böylece yapılan tanıtım tüketiciler tarafından gerçekçi ve güvenilir bulunmaktadır (Hall, 2016). Fenomenlerin takipçileriyle kurdukları güvenilir ilişkiler, onların sayfasında ya da bloklarında önerdikleri herhangi bir ürün ya da markanın tercih edilme ihtimalini arttırabilmektedir.

Sosyal medya platformları üzerinden gerçekleştirilen fenomen pazarlaması üç temel özelliğe sahiptir (Mallipeddi vd., 2018:2):

1. Sosyal medya fenomenleri herhangi bir aracı kullanmadan takipçileri ile doğrudan iletişim kurmaktadır.

2. Sosyal medya platformları mesajların yayılmasını kolaylaştırmakta, bu durum da fenomen pazarlamasının başarısında önemli bir rol oynamaktadır. Mesajların yayılma sürecinde fenomenler sosyal medya üzerinden direkt kendi takipçileri ve onların dışında doğrudan takipçisi olmayan takipçilerinin takipçilerine de ulaşabilmektedirler.

3. Sosyal medya, firmaların etkinliklerin sonuçlarını etkili bir şekilde ölçümlemelerine izin vermektedir.

Fenomenleri de dört kategori altında incelemek mümkündür (Ranga ve Sharma, 2014:18):

1. Geleneksel fenomenler: Belirli bir alanda uzmanlığa sahip, geleneksel halkla ilişkiler ajanslarında çalışan bireyler veya ünlü figürlerdir.

2. Dijital fenomenler: Poster-tech blogerlar ve dijital fenomenler belirli bir alan içerisinde yürütmüş oldukları liderlikle dikkate değer geniş bir topluluğa sahiptirler.

3. Bağlantı yoluyla fenomen olanlar: $\mathrm{Bu}$ tür fenomenlerin yüzlerce Facebook arkadaşı ve Twitter'da takipçileri bulunmaktadır.

4. Belirli bir konu ile ilgili fenomenler: Bu insanlar, belirli bir konu ile ilgili olarak kanaat önderliği yapmaktadırlar.

Firmalar, bir ürün ya da markanın reklamını ya da tanıtımını yapmak üzere, hedef kitleye göre seçecekleri bu farklı türdeki fenomenlerle bağlantıya geçebilmekte, hatta bu kişilerle sürekli 
bağlantıda olup yeni çıkan ürünleri takipçilerine duyurmaları ve tanıtmaları konusunda anlaşabilmektedirler.

\section{Yöntem}

\subsection{Araştırma Amacı}

Çalışmada; sosyal medyada ücretsiz fotoğraf ve video paylaşma uygulaması olan Instagram'da fenomen haline gelen annelerin kendi hesaplarında yapmış oldukları paylaşımların içeriklerini inceleyerek ve bu annelerin hesapları üzerinden tanıtımını yaptıkları ürün ve markaları ele alarak fenomen pazarlamasının nasıl işlediğini ortaya koymak amaçlanmıştır.

\subsection{Araştırma Grubu}

2019 verileri incelendiğinde (http://www.hurriyetaile.com/fotogaleri/ebeveyn/hepsi-birerfenomen-instagramin-populer-anneleri-4308,https://onedio.com/haber/kim-bu-insanlar-nedenbinlerce-takipcileri-var-paylastiklari-ve-yaptiklariyla-her-daim-merak-edilen-16-instagramannesi-817697), Instagram'da takipçi sayıları en yüksek 16 fenomen annenin ön plana çıtığı görülmüştür, fakat 16 anneden 2'sinin (Oyuncuanne ve Manyakanne) hesaplarına erişim sağlanamamıştır. Bu nedenle, aktif Instagram kullanıcısı olan 14 fenomen annenin hesapları 01.03.2020-30.03.2020 tarihlerinde incelenmiş ve belirlenen kategoriler çerçevesinde içerik analizi gerçekleştirilmiştir.

\subsection{Araştırma Yöntemi}

İçerik analizi nitel bir araştırma yöntemidir. Nitel araştırmalar kendi içerisinde çok fazla sayıda uygulanabilmekte ve farklı analizler çerçevesinde yürütülebilmektedir. Nitel araştırma; karmaşık, değişken, tartışmalı birçok yöntem ve araştırmayı kapsamaktadır. Nitel araştırma, dolayısıyla tek 
bir varlığı değil, devasa bir çeşitliliği kapsayan şemsiye bir terimdir (Punch, 2014:132). İçerik analizi; "bir veya birçok metnin içindeki sözcüklerin, kavramların, temaların, deyimlerin, karakterlerin veya cümlelerin varlıklarını belirlemek ve onları sayıya dökmek için kullanılmaktadır" (Kızıltepe, 2015:253).

\subsection{Araştırma Soruları}

Araştırma kapsamında belirlenen 13 kategori doğrultusunda oluşturulan araştırma soruları aşağıda yer almaktadır:

1.Fenomen annelerin takipçi sayıları ne kadardır?

2.Fenomen annelerin takip ettikleri kişi sayısı kaçtır?

3.Fenomen annelerin Instagram profillerinde yer alan toplam paylaşım sayısı kaç adettir?

4.Fenomen annelerin 2019 yılındaki paylaşım sayıları nedir?

5.Fenomen annelerin 2019 yılında yaptıkları herhangi bir ürün/markayla ilgili paylaşım sayıları nedir?

6.Fenomen annelerin 2019 yılında herhangi bir ürün/markayla ilgili paylaştıkları video sayıları nedir?

7.Fenomen anneler en çok hangi aylarda ürün ya da marka içerikli paylaşım yapmışlardır?

8.En çok paylaşım yapılan ürün ya da markalar içinde ilk sırada yer alan hangisidir?

9.İlk sırada yer alan ürün ya da markayla ilgili paylaşımların beğeni sayıları nedir?

10.İlk sırada yer alan ürün ya da marka hangi kategoride yer almaktadır?

11.Ürün ya da marka ile ilgili paylaşımlarda kullanılan hashtagler nelerdir?

12.En çok yorum alan ürün ya da markalar hangileridir?

13.En çok yorum alan ürün ya da markalara yapılan yorum sayıları nedir? 


\section{Bulgular}

Belirlenen kategoriler ve araştırma soruları doğrultusunda yapılan analizler sonucu aşağıdaki bulgulara ulaşılmıştır. Bu bulgulardan sırasıyla bahsedilecektir.

Tablo 1: Fenomen Annelerin Takipçi Sayıları

\begin{tabular}{|c|c|}
\hline Fenomen Anneler & Takipçi Sayıları \\
\hline Akademisyenanne & 980.000 \\
\hline Puccito & 683.000 \\
\hline İmren Gürsoy & 492.000 \\
\hline $\begin{array}{l}\text { Zynepzeze(Zeynep } \\
\text { Özbayrak) }\end{array}$ & 420.000 \\
\hline Gizem Zor & 372.000 \\
\hline $\begin{array}{l}\text { Ollaluna(Yeliz } \\
\text { Y1lmaz) }\end{array}$ & 337.000 \\
\hline $\begin{array}{l}\text { Melinas Mom(Merve } \\
\text { İpek Öztürk) }\end{array}$ & 316.000 \\
\hline Esgimira & 315.000 \\
\hline Gül Küvetin & 193.000 \\
\hline $\begin{array}{l}\text { Pembe Koala(Funda } \\
\text { Korkut) }\end{array}$ & 179.000 \\
\hline Zeynep Gözübüyük & 151.000 \\
\hline $\begin{array}{l}\text { Kokoshanne(Meltem } \\
\text { Bicioğlu) }\end{array}$ & 133.000 \\
\hline $\begin{array}{l}\text { Blogcuanne(Elif } \\
\text { Doğan) }\end{array}$ & 112.000 \\
\hline $\begin{array}{l}\text { Turuncubikız(Funda } \\
\text { Karakılıç) }\end{array}$ & 107.000 \\
\hline
\end{tabular}

Instagram'da fenomen olan 14 annenin takipçi sayıları incelendiğinde, bu sayıların 107.000 ile 980.000 arasında değiştiği görülmektedir. Tablo 1'de yer alan bu rakamlar 2020 Mart ayı itibariyle 
belirlenen rakamlardır. Buna göre; "Akademisyenanne" rumuzunu kullanan fenomen anne Saniye Bencik Kangal, 980.000 takipçi ile birinci sırada yer almaktadır.

Tablo 2: Fenomen Annelerin Takip Ettikleri Kişi Sayısı

\begin{tabular}{|l|c|}
\hline Fenomen Anneler & $\begin{array}{l}\text { Takip Edilen Kişi } \\
\text { Sayısı }\end{array}$ \\
\hline $\begin{array}{l}\text { Akademisyenanne (Saniye Bencik } \\
\text { Kangal) }\end{array}$ & 345 \\
\hline Puccito & 1.411 \\
\hline İmren Gürsoy & 466 \\
\hline Zynepzeze (Zeynep Özbayrak) & 505 \\
\hline Gizem Zor & 881 \\
\hline Ollaluna (Yeliz Yılmaz) & 1.013 \\
\hline Melinas Mom (Merve İpek Öztürk) & 330 \\
\hline Esgimira (Ezgi Develi) & 652 \\
\hline Gül Küvetin & 940 \\
\hline Pembe Koala (Funda Korkut) & 984 \\
\hline Zeynep Gözübüyük & 832 \\
\hline Kokoshanne (Meltem Bicioğlu) & 284 \\
\hline Blogcuanne (Elif Doğan) & \\
\hline Turuncubikız (Funda Karakılıç) & \\
\hline
\end{tabular}

Tablo 2'de yer alan, fenomen annelerin takip ettikleri kişi sayıları incelendiğinde, bu annelerin takip ettikleri kişi sayılarının onları takip eden kişi sayıları kadar yüksek olmadığı anlaşılmaktadır. 
En çok takipçisi olan Akademisyenanne rumuzlu Saniye Bencik Kangal'ın takip ettiği kişi sayısının listedeki en düşük takip edilen kişi sayılarından biri olması diğer ilginç bir sonuçtur.

Tablo 3: Toplam Paylaşım Sayısı

\begin{tabular}{|l|c|}
\hline Fenomen Anneler & $\begin{array}{l}\text { Toplam } \\
\text { Sayısı }\end{array}$ \\
\hline $\begin{array}{l}\text { Akademisyenanne (Saniye Bencik } \\
\text { Kangal) }\end{array}$ & 4.504 \\
\hline Puccito & 2.227 \\
\hline İmren Gürsoy & 4.114 \\
\hline Zynepzeze (Zeynep Özbayrak) & 3.376 \\
\hline Gizem Zor & 1.680 \\
\hline Ollaluna (Yeliz Yılmaz) & 4.194 \\
\hline Melinas Mom (Merve İpek Öztürk) & 7.514 \\
\hline Esgimira (Ezgi Develi) & 8.490 \\
\hline Gül Küvetin & 2.313 \\
\hline Pembe Koala (Funda Korkut) & 3.261 \\
\hline Zeynep Gözübüyük & 7.129 \\
\hline Kokoshanne (Meltem Bicioğlu) & 3.296 \\
\hline Blogcuanne (Elif Doğan) & 9.966 \\
\hline Turuncubikız (Funda Karakılıç) & 3.857 \\
\hline
\end{tabular}

Araştırma kapsamında; fenomen annelerden bazılarının Instagram hesaplarını 3 yıldır bazılarının ise 3 yıldan fazla süredir kullandığı belirlenmişstir. Dolayısıyla, toplam paylaşım sayıları Instagram'ın kullanılma süresine bağlı olarak değişkenlik göstermiş̧ir. Tablo 3'de de görüleceği 
gibi; fenomen anneler içerisinde toplam paylaşım sayısı en fazla olan, 9.966 paylaşım ile Blogcu anne rumuzlu Elif Doğan'dır. İkinci sırada 8.490 paylaşım ile Esgimira rumuzlu Ezgi Mira Develi'nin, üçüncü sırada ise 7.514 paylaşım ile Melinas Mom rumuzlu Merve İpek Öztürk'ün yer aldığı görülmektedir.

Tablo 4: Fenomen Annelerin 2019 Yılına Ait Paylaşım Sayıları

\begin{tabular}{|l|c|}
\hline Fenomen Anneler & Paylaşım Sayıları \\
\hline $\begin{array}{l}\text { Akademisyenanne (Saniye Bencik } \\
\text { Kangal) }\end{array}$ & 695 \\
\hline Puccito & 330 \\
\hline İmren Gürsoy & 336 \\
\hline Zynepzeze (Zeynep Özbayrak) & 335 \\
\hline Gizem Zor & 198 \\
\hline Ollaluna (Yeliz Yılmaz) & 304 \\
\hline Melinas Mom (Merve İpek Öztürk) & 510 \\
\hline Esgimira (Ezgi Develi) & 84 \\
\hline Gül Küvetin & 193 \\
\hline Pembe Koala (Funda Korkut) & 520 \\
\hline Zeynep Gözübüyük & 322 \\
\hline Kokoshanne (Meltem Bicioğlu) & 597 \\
\hline Blogcuanne (Elif Doğan) & 201 \\
\hline Turuncubikız (Funda Karakılıç) & \\
\hline
\end{tabular}

Tablo 4'de yer alan 2019 yılına ait paylaşım sayıları incelendiğinde, takipçi sayısı yüksek olan Akademisyenanne'nin 695 paylaşım ile birinci sırada olduğu görülmektedir. Bu fenomen annenin 
yapmış olduğu paylaşımlar yoğunlukta olarak uzmanlık alanı olan çocuk gelişimi ilgilidir ve çocukların gelişimini olumlu yönde etkileyebilecek oyunlar paylaşmaktadır. İkinci sırada 597 paylaşım ile yer alan Blogcuanne rumuzlu Elif Doğan'ın kendi hayatına ve çocuklarına yönelik paylaşımlara yer vermiş olduğu, 520 paylaşım ile üçüncü sırada yer alan Zeynep Gözübüyük'ün ise uzman olduğu hamile yogası, anne bebek yogası, hamile pilatesi gibi konularda paylaşımlar yaptığı görülmüştür.

Tablo 5: Fenomen Annelerin 2019 Yılında Yaptıkları Herhangi Bir Ürün/Markayla İlgili Paylaşım Sayılar1

\begin{tabular}{|l|c|}
\hline Fenomen Anneler & Ürün ve Marka Sayısı \\
\hline $\begin{array}{l}\text { Akademisyenanne (Saniye Bencik } \\
\text { Kangal) }\end{array}$ & $*$ \\
\hline Puccito & 2 \\
\hline İmren Gürsoy & 26 \\
\hline Zynepzeze (Zeynep Özbayrak) & 95 \\
\hline Gizem Zor & 44 \\
\hline Ollaluna (Yeliz Yılmaz) & 110 \\
\hline Melinas Mom (Merve İpek Öztürk) & 152 \\
\hline Esgimira (Ezgi Develi) & 35 \\
\hline Gül Küvetin & 49 \\
\hline Pembe Koala (Funda Korkut) & 323 \\
\hline Zeynep Gözübüyük & 154 \\
\hline Kokoshanne (Meltem Bicioğlu) & \\
\hline Blogcuanne (Elif Doğan) & \\
\hline Turuncubikız(Funda Karakılıç) & \\
\hline
\end{tabular}

Belirli bir kitleye sahip olan ve bu kitleleri yaptıkları paylaşımlarla etkileyebilen fenomenler, sosyal medya hesaplarında anlaştıkları firmaların markalarına yer vererek kitleleri bu markaları 
kullanma konusunda ikna edebilmekte ve satın almaya yönlendirebilmektedirler. Fenomen annelerin Instagram hesaplarında yer alan 2019 yılına ait 4.734 paylaşım incelenmiş ve yaptıkları çeşitli markalara ilişkin paylaşım sayılarına Tablo 5'de yer verilmiştir. İncelenen bu paylaşımlar doğrultusunda, en fazla paylaşım sayısının 323 paylaşımla Zeynep Gözübüyük isimli fenomen anneye ait olduğu görülmüştür. Anne-bebek yogası, hamile yogası ve hamile pilatesi konularında eğitimler almış olan Zeynep Gözübüyük, bu eğitimleri belirli markaların sponsorluğunda farklı yerlerde anneler ile bir araya gelerek düzenlemektedir. Paylaşımlarında, bu eğitimlere sponsorluk yapmış olan markalara yer vermiş olduğu ve eğitimlere katılan annelere ve anne adaylarına bu markalar hakkında bilgi vererek marka ve potansiyel müşteri arasında köprü görevi görmeye çalıştı̆̆ anlaşılmıştır.

Tablo 6: Fenomen Annelerin 2019 Yılında Herhangi Bir Ürün/Marka ile İlgili Paylaştıkları Video Sayıları

\begin{tabular}{|l|c|}
\hline Fenomenler & Paylaşılan Videolar \\
\hline $\begin{array}{l}\text { Akademisyenanne (Saniye Bencik } \\
\text { Kangal) }\end{array}$ & $*$ \\
\hline Puccito & 2 \\
\hline İmren Gürsoy & 3 \\
\hline Zynepzeze (Zeynep Özbayrak) & 4 \\
\hline Gizem Zor & 3 \\
\hline Ollaluna (Yeliz Yılmaz) & 8 \\
\hline Melinas Mom (Merve İpek Öztürk) & 11 \\
\hline Esgimira (Ezgi Develi) & $*$ \\
\hline Gül Küvetin & $*$ \\
\hline Pembe Koala (Funda Korkut) & 35 \\
\hline Zeynep Gözübüyük & \\
\hline
\end{tabular}




\begin{tabular}{|l|c|}
\hline Kokoshanne (Meltem Bicioğlu) & 5 \\
\hline Blogcuanne (Elif Doğan) & 2 \\
\hline Turuncubikız(Funda Karakılıç) & 4 \\
\hline
\end{tabular}

Fenomen anneler paylaşımlarında genel olarak kullanmış oldukları markalar, bu markalarla ilgili deneyimleri ve bu markalar hakkında merak edilen konulara yönelik hedef kitlelerini bilgilendirmektedirler. Bu paylaşımları kimi zaman fotoğraflar eşliğinde, kimi zaman da video çekerek yapmaktadırlar. Yapılan paylaşımlar incelendiğinde, fenomen annelerin genel olarak paylaşımlarında video çekimini tercih etmedikleri anlaşılmıştır. Tablo 6'da, Zeynep Gözübüyük isimli fenomenin 35 paylaşımda video'ya yer vermiş olduğu ve bu paylaşımlarında genel olarak anne-bebek yogası, hamile yogası ve hamile pilatesi konularında yapmış olduğu etkinliklerden kesitlerin yer aldığı görülmektedir. Video paylaşım sayısında ikinci sırada yer alan fenomen anne Esgimira rumuzlu Ezgi Develi ise çeşitli markalar konusunda hedef kitlelerini bilgilendirme amaçlı video çekmiştir. Üçüncü sırada yer alan Melinasmom rumuzlu Merve İpek Öztürk’ün de farklı markalara yönelik yaptığı işbirlikleri doğrultusunda çeşitli videolar çekmiş olduğu görülmüştür.

Tablo 7: Fenomen Annelerin Ürün/Marka İçerikli Paylaşımlarının En Yüksek Olduğu Aylar

\begin{tabular}{|c|c|c|c|c|c|c|c|c|c|c|c|c|}
\hline $\begin{array}{l}\text { Feno } \\
\text { men } \\
\text { Annel } \\
\text { er }\end{array}$ & $\begin{array}{c}\text { Oca } \\
\mathbf{k}\end{array}$ & $\begin{array}{c}\text { Şub } \\
\text { at }\end{array}$ & $\begin{array}{c}\text { Mar } \\
\mathbf{t}\end{array}$ & $\begin{array}{c}\text { Nisa } \\
\text { n }\end{array}$ & $\begin{array}{c}\text { May } \\
\text { IS }\end{array}$ & $\begin{array}{c}\text { Hazir } \\
\text { an }\end{array}$ & $\begin{array}{c}\text { Temm } \\
\text { uz }\end{array}$ & $\begin{array}{c}\text { A ğust } \\
\text { os }\end{array}$ & $\begin{array}{c}\text { Eylü } \\
\text { l }\end{array}$ & $\begin{array}{c}\text { Eki } \\
\text { m }\end{array}$ & $\begin{array}{c}\text { Kasi } \\
\text { m }\end{array}$ & $\begin{array}{c}\text { Aral } \\
\text { lk }\end{array}$ \\
\hline $\begin{array}{l}\text { Akade } \\
\text { misye } \\
\text { nanne } \\
\text { (Saniy }\end{array}$ & & & & & & & & & & & & \\
\hline
\end{tabular}




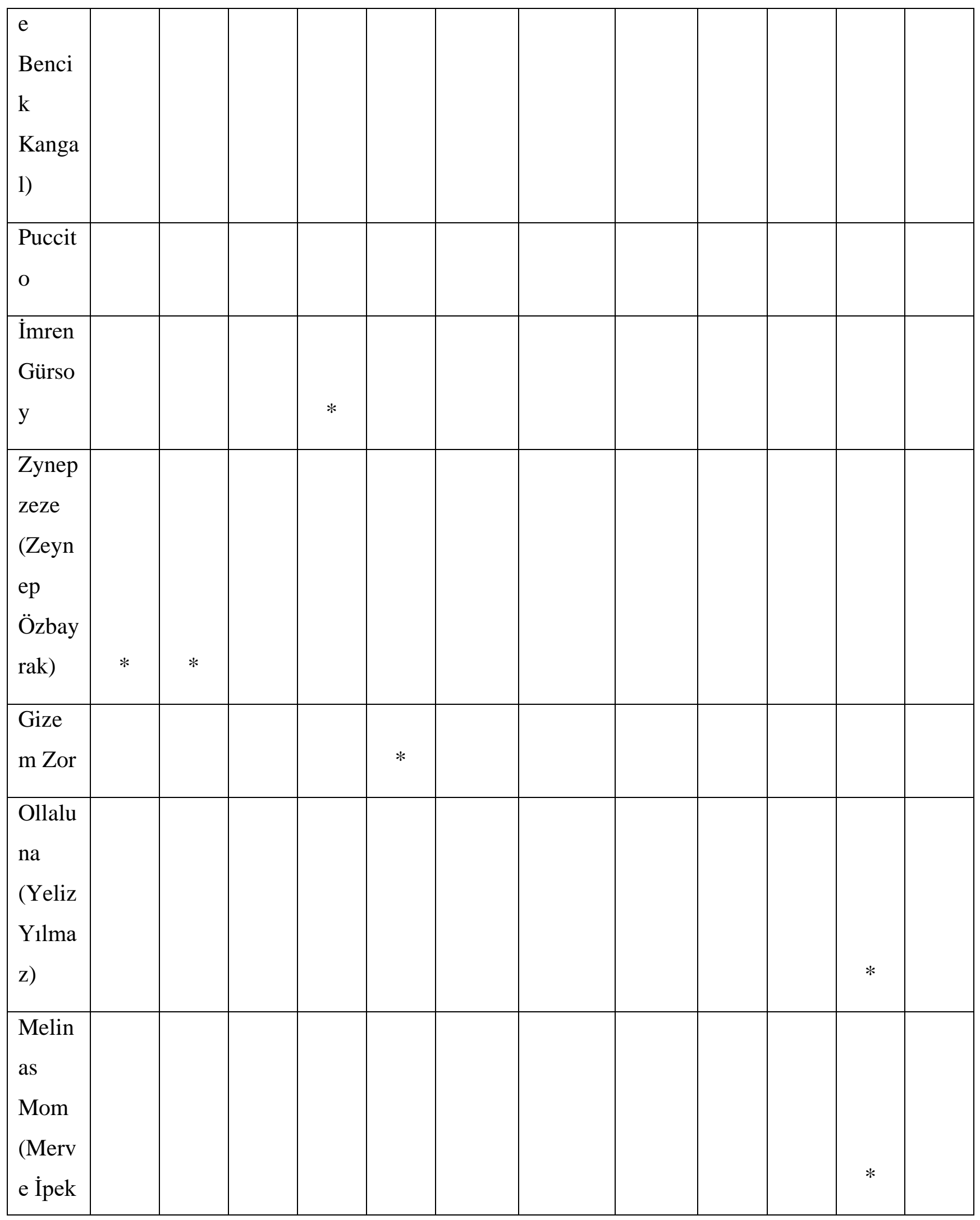


Fenomen Pazarlaması: Fenomen Anneler Üzerine Bir İçerik Analizi

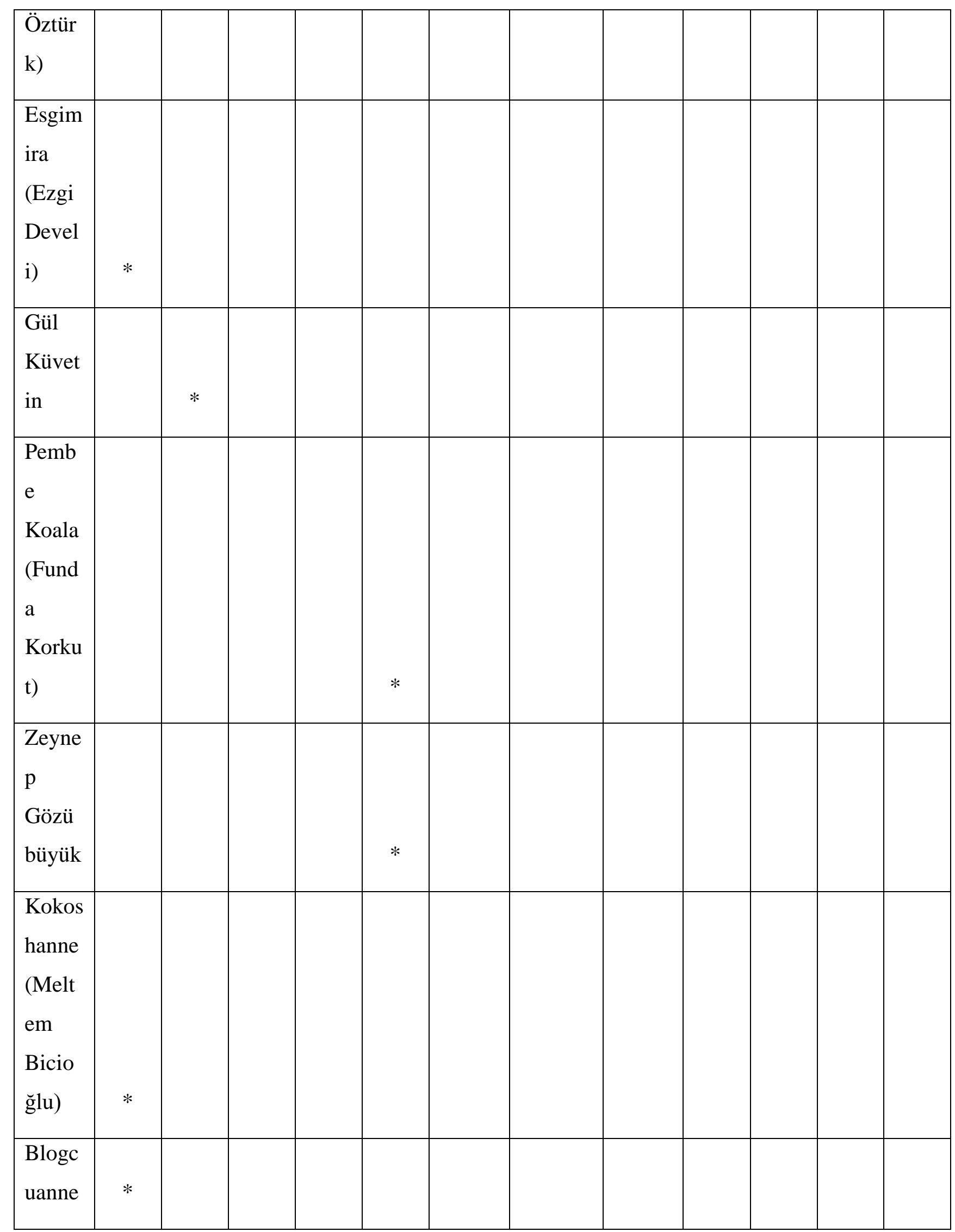




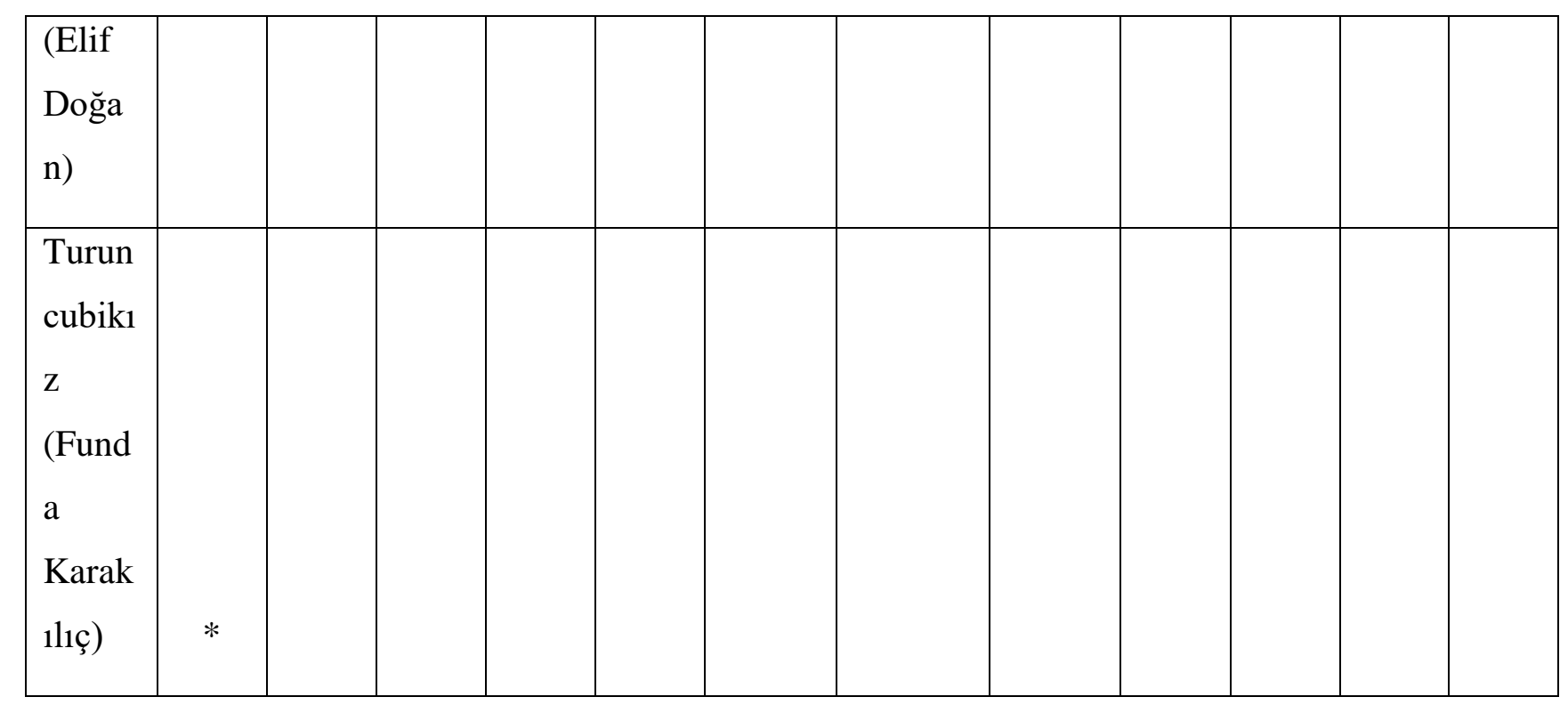

12 ay baz alınarak, fenomen annelerin ürün/marka içerikli en çok hangi aylarda paylaşım yaptıkları incelenmiş ve bu aylar '*' işareti ile gösterilmiştir. Paylaşım sayıları çoktan aza göre sıralandığında; Ocak ayında 67 paylaşım ile Blogcu anne, Mayıs ayında 58 paylaşım ile Zeynep Gözübüyük, Ocak ayında 55 paylaşım ile Esgimira, Ocak ayında 47 paylaşım ile Kokoshanne, Kasım ayında 39 paylaşım ile Melinasmom, Mayıs ayında 32 paylaşım ile Gizem Zor, Ocak ayında 32 paylaşım ile Turuncubikız, Kasım ayında 29 paylaşım ile Ollaluna, Mayıs ayında 27 paylaşım ile Pembe Koala, Şubat ayında 14 paylaşım ile Gül Küvetin, Nisan ayında 10 paylaşım ile İmren Gürsoy, Ocak ve Şubat aylarında 3'er paylaşım ile Zynepzeze yer almaktadır. Fenomen annelerin en çok Ocak ayında, ikinci olarak da Mayıs ayında paylaşım yaptıkları anlaşılmıştır.

Tablo 8: En Çok Paylaşım Yapılan Ürün/Markalar, Yer Aldıkları Kategoriler ve Beğeni Sayıları

\begin{tabular}{|l|c|c|c|}
\hline $\begin{array}{l}\text { Fenomen } \\
\text { Anneler }\end{array}$ & $\begin{array}{l}\text { Ürün/ } \\
\text { Marka }\end{array}$ & $\begin{array}{c}\text { Ürün/Markanın Yer } \\
\text { Aldı̆̆ı Kategori }\end{array}$ & Beğeni Sayısı \\
\hline $\begin{array}{l}\text { Akademisyenann } \\
\text { e (Saniye Bencik } \\
\text { Kangal) }\end{array}$ & $*$ & $*$ & $*$ \\
\hline
\end{tabular}


Fenomen Pazarlaması: Fenomen Anneler Üzerine Bir İçerik Analizi

\begin{tabular}{|c|c|c|c|}
\hline Puccito & $\begin{array}{l}\text { Kitap } \\
\text { İmza } \\
\text { Günü }\end{array}$ & Kültür/Sanat & 43.201 \\
\hline İmren Gürsoy & Cambly & Eğitim & 168.523 \\
\hline $\begin{array}{l}\text { Zynepzeze } \\
\text { (Zeynep } \\
\text { Özbayrak) }\end{array}$ & Foreo & Kozmetik & 771.540 \\
\hline Gizem Zor & Cambly & Eğitim & 153.768 \\
\hline $\begin{array}{l}\text { Ollaluna (Yeliz } \\
\text { Y1lmaz) }\end{array}$ & Flormar & Kozmetik & 175.630 \\
\hline $\begin{array}{l}\text { Melinas Mom } \\
\text { (Merve İpek } \\
\text { Öztürk) }\end{array}$ & $\begin{array}{l}\text { Brita } \\
\text { Akıllı } \\
\text { Sürahi }\end{array}$ & Küçük Ev Aletleri & 40.720 \\
\hline $\begin{array}{l}\text { Esgimira (Ezgi } \\
\text { Develi) }\end{array}$ & $\begin{array}{l}\text { Bahar } \\
\text { Dönen }\end{array}$ & Kozmetik & 21.670 \\
\hline Gül Küvetin & Medikil & Sağlık & 8.198 \\
\hline $\begin{array}{l}\text { Pembe Koala } \\
\text { (Funda Korkut) }\end{array}$ & $\begin{array}{c}\text { Little } \\
\text { Posers } \\
\text { Fine Arts }\end{array}$ & Fotoğraf Stüdyosu & 17.789 \\
\hline $\begin{array}{l}\text { Zeynep } \\
\text { Gözübüyük }\end{array}$ & Joker & Bebek/Çocuk Ürünleri & 7.951 \\
\hline $\begin{array}{l}\text { Kokoshanne } \\
\text { (Meltem } \\
\text { Bicioğlu) }\end{array}$ & $\begin{array}{l}\text { Kindi } \\
\text { Kids }\end{array}$ & Oyuncak & 9.781 \\
\hline $\begin{array}{l}\text { Blogcuanne (Elif } \\
\text { Doğan) }\end{array}$ & $\begin{array}{l}\text { Tribu } \\
\text { Caffe }\end{array}$ & İşletme & 3.958 \\
\hline
\end{tabular}




\begin{tabular}{|l|c|c|c|}
\hline Turuncubikız & Ysl, \\
(Funda Karakılıç) & $\begin{array}{c}\text { Rueonline, } \\
\text { Raivannes }\end{array}$ & Giyim & \\
& $\mathrm{a}$ & & \\
& & 9.237 \\
\hline
\end{tabular}

8. 9. ve 10. araştırma sorularına iliş̧kin bulgular Tablo 8'de yer almaktadır. Elde edilen bu bulgular doğrultusunda, Akademisyen anne rumuzlu fenomen annenin herhangi bir marka ile işbirliği içerisinde olmadığ belirlenmiştir. Tablo 8'de, diğer 13 fenomen annenin hangi ürün/markalara ilişkin paylaşım yaptıklarına, bu ürün/markaların hangi kategoride olduğuna ve bu ürün/marka ile ilgili paylaşımlara ait beğeni sayılarına yer verilmiştir. Fenomen annelerin paylaşımlarında en çok yer verdikleri ürün/markaların hangi kategorilerde olduğu incelendiğinde, bu kategorilerin; eğitim, kültür/sanat, kozmetik, küçük ev aletleri, fotoğraf stüdyosu, sağlık, bebek/çocuk ürünleri, oyuncak, işletme ve giyim şeklinde olduğu görülmüştür. Fenomen annelerin en çok beğeni alan ürün/markalarla ilgili paylaşımları ele alındığında ise ilk üç sıra şu şekildedir: (1) 771.540 beğeni ile Zynepzeze rumuzlu fenomen annenin kozmetik sektöründe yer alan Foreo markası ile ilgili paylaşımı, (2) 175.630 beğeni ile Ollaluna rumuzlu fenomen annenin kozmetik sektöründe yer alan Flormar markası ile ilgili paylaşımı, (3) 168.523 beğeni ile İmren Gürsoy isimli fenomen annenin eğitim sektöründe yer alan Camblyt markası ile ilgili paylaşımı. Tablo 8 incelendiğinde, fenomen annelerin kozmetik sektöründe yer alan markalarla ilgili paylaşımlarının beğeni oranlarının yüksek olduğu anlaşılmaktadır. Bunun, takipçilerin çoğunluğunun kendileri gibi kadınlardan oluşmasından kaynaklandığını söylemek mümkündür.

Tablo 9: Reklamı Yapılan Ürün/Markalarla İlgili Hashtagler

\begin{tabular}{|l|l|}
\hline Fenomen Anneler & Hashtag \\
\hline Akademisyenanne (Saniye Bencik Kangal) & $*$ \\
\hline Puccito & Kırmızıkitapevi \\
\hline İmren Gürsoy & Camblyt \\
\hline
\end{tabular}


Fenomen Pazarlaması: Fenomen Anneler Üzerine Bir İçerik Analizi

\begin{tabular}{|l|l|}
\hline Zynepzeze(Zeynep Özbayrak) & Foreo \\
\hline Gizem Zor & Kissmemore, kissmemorechallenge \\
\hline Ollaluna (Yeliz Yılmaz) & $\begin{array}{l}\text { Camblyt, Hediye, İngilizce, } \\
\text { İngilizceders }\end{array}$ \\
\hline Melinas Mom (Merve İpek Öztürk) & Brita Akıllı Sürahi \\
\hline Esgimira (Ezgi Develi) & Bahardonen \\
\hline Gül Küvetin & $\begin{array}{l}\text { Medikil, maske, bentonitkili, } \\
\text { bentonit, kilmaskesi }\end{array}$ \\
\hline Pembe Koala (Funda Korkut) & $\begin{array}{l}\text { Littleposersfinearts } \\
\text { Hediye, çekiliş, internetanneleri, } \\
\text { uykusuzanneler, } \\
\text { hamile, pumileanneler, bebek, hediye, } \\
\text { doğumhediyesi, hamileyiz }\end{array}$ \\
\hline Zeynep Gözübüyük & Kindikidsofficial \\
\hline $\begin{array}{l}\text { Kuruncubikız } \\
\text { (Funda Karakılıç) }\end{array}$ & \begin{tabular}{l} 
Bizvediğerşeyler \\
\hline Blogcuanne (Elif Doğan)
\end{tabular} \\
\hline
\end{tabular}

Tablo 9'da fenomen annelerin beğeni sayısı en yüksek olan markalar ile ilgili hashtagleri yer almaktadır. Örneğin; Puccito rumuzlu fenomen annenin yaptığı paylaşımda Kırmızı Kitap Evi etiketlenerek aynı zamanda hashtagte de yer almıştır. Camblyt, Foreo, Brita, Bentonit, Kindi Kids gibi markaların hashtaglerde de olduğu görülmüştür. Bununla birlikte, Akademisyenanne ve Blogcuannenin yaptığı paylaşımlarda hashtaglerin olmadığı anlaşılmıştır. 
Tablo 10: Fenomen Annelerin Paylaşım Yaptıkları Ürün/Markalar İçinde En Çok Yorum Alanlar ve Yorum Sayıları

\begin{tabular}{|c|c|c|}
\hline Fenomen Anneler & $\begin{array}{c}\text { En Çok Yorum Alan } \\
\text { Ürün/Marka }\end{array}$ & Yorum Sayıları \\
\hline $\begin{array}{l}\text { Akademisyenanne (Saniye Bencik } \\
\text { Kangal) }\end{array}$ & $*$ & $*$ \\
\hline Puccito & $\begin{array}{c}\text { * } \\
\text { (Marka değil, sadece } \\
\text { görsel paylaşılmıştır.) }\end{array}$ & 949 \\
\hline İmren Gürsoy & Mopak & 86.330 \\
\hline Zynepzeze (Zeynep Özbayrak) & Trendyolmilla & 188.568 \\
\hline Gizem Zor & Gezen Bebe & 40.165 \\
\hline Ollaluna (Yeliz Y1lmaz) & Flormar & 13.685 \\
\hline Melinas Mom (Merve İpek Öztürk) & İsabel Abbey & 32.569 \\
\hline Esgimira (Ezgi Develi) & Evmila & 22.239 \\
\hline Gül Küvetin & Mavi, Crfrsa Bursa AVM & 38.378 \\
\hline Pembe Koala (Funda Korkut) & Firstmoon Art & 11.594 \\
\hline Zeynep Gözübüyük & Joker Baby & 61.787 \\
\hline Kokoshanne (Meltem Bicioğlu) & Everly Grey & 1.540 \\
\hline Blogcuanne (Elif Doğan) & Defacto & 203 \\
\hline Turuncubikız (Funda Karakılıç) & Gusto Giyim & 3.259 \\
\hline
\end{tabular}

Tablo 10'da 12. ve 13. araştırma sorularına ilişkin bulgulara yer verilmiştir. Tabloda, her bir fenomen annenin paylaşım yaptığı ürün/markalar içinde en çok yorum alanlar ve bu ürün/markalarla ilgili yorum sayıları yer almaktadır. Yorum sayıları göz önüne alındığında; Zynepzeze rumuzlu fenomen annenin paylaşım yaptığı Trendyolmilla markasının 188.568 
yorumla birinci sırada, İmren Gürsoy adlı fenomen annenin paylaşım yaptı̆̆ Mopak markasının 86.330 yorumla ikinci sırada, Zeynep Gözübüyük adlı fenomen annenin paylaşım yaptığı Joker baby markasının 61.787 yorumla üçüncü sırada olduğu görülmektedir. En çok yorum alan markaların yer aldığı kategoriler; giyim, kırtasiye, bebek ürünleri, kozmetik, alışveriş merkezi şeklindedir.

\section{Sonuç, Tartışma ve Öneriler}

Marka tercihi çeşitli faktörlere bağlı olarak değişkenlik gösterebilmektedir. Günümüzde, tüketiciler hangi ürün ya da markayı tercih etmeleri gerektiğine karar verme aşamasında bilgi toplamak amacıyla detaylı araştırmalar yapabilmekte ya da uzman görüşüne başvurma yoluna gidebilmektedirler. Bilgi toplama konusunda özellikle sosyal medyanın oldukça önemli bir yeri bulunmaktadır. Çeşitli demografik, sosyo-grafik ve psikografik özelliklere sahip bireyler sosyal medya aracıllğıyla ürün ya da marka konusunda uzman ya da deneyimli kişilerden bilgi toplayabilmektedir. Ayrıca son yıllarda pazarlamacılar, ürünleri ya da markaları tanıtmak amacıyla tanınırlığı ve bilinirliği yüksek olan bireyleri kullanmaya ve bu kişilerle tüketiciler arasında köprü kurmaya başlamışlardır. Ünlü olsun veya olmasın fenomen olarak isimlendirilen bu kişiler, çeşitli sosyal medya platformlarında güçlü bir izleyici kitlesine sahip ve içerik ürettiği alanda düşüncelerine önem verilen kişilerdir. Bu nedenle; tüketiciler sosyal medyada takip ettikleri bu kişilerin önerilerini dikkate alabilmekte, onlardan etkilenerek ürün ya da marka tercihi yapabilmektedirler.

Pazarlama literatürüne fenomen pazarlaması şeklinde giren bu pazarlama şeklinde, tüketiciler ile firmalar arasındaki ilişkiler farklı bir boyut kazanmıştır. Fenomen pazarlamasında deneyim ön plana çıkmakta, fenomenler ürün ve marka hakkında bilgiler vererek, çeşitli içeriklerde paylaşımlar yaparak tüketicileri bu ürün veya markayı satın alma konusunda ikna etmeye çalışmaktadırlar. Takipçi sayısı çok yüksek olan ve düşüncelerine önem verilen bu kişilerin tüketicilerin satın alma kararlarında etkisi büyük olmaktadır. 
Çalışma kapsamında, ele alınan 14 Instagram fenomeni annenin hesapları incelenerek belirlenen araştırma soruları doğrultusunda analizler gerçekleştirilmiş ve çeşitli bulgular elde edilmiştir. $\mathrm{Bu}$ bulgular ışığında şu sonuçlara ulaşılmıştır:

* Fenomen annelerin takipçi sayıları ile onların takip ettikleri kişi sayılarının doğru orantılı olmadığı görülmüştür. Örneğin, Akademisyenanne rumuzlu Saniye Bencik Kangal'ın takip ettiği kişi sayısı takipçi sayısının on binde 4'ü bile değildir.

* Fenomen annelerin toplam paylaşım sayılarının yüksek olması takipçileriyle sık iletişim kurmaya çalıştıklarını göstermektedir.

* Fenomen annelerin 2019 yılında yaptıkları ürün/markalarla ilgili paylaşım sayıları incelendiğinde, bu yıl içerisinde yaptıkları toplam paylaşım sayılarına göre farklı oranlarda gerçekleştiği görülmüştür. Örneğin, 2019 yılı içinde en çok paylaşım yapan Akademisyenanne rumuzlu Saniye Bencik Kangal ürün ya da marka içerikli herhangi bir paylaşım yapmamıştır. Bunun nedeninin bu fenomen annenin aynı zamanda öğretim üyesi olmasından kaynaklandığ 1 düşünülmektedir. Yine, 2019 yılındaki paylaşım sayılarına göre ikinci sırada olan Blogcuanne rumuzlu Elif Doğan'ın da sadece 72 adet ürün/marka içerikli paylaşım yaptığı görülmüştür.

* Fenomen annelerin herhangi bir ürün ya da markayla ilgili çok az video paylaştıkları belirlenmiştir.

* Fenomen annelerin ürün/marka içerikli en çok Ocak ayında, ikinci olarak da Mayıs ayında paylaşım yaptıkları görülmüştür.

*Fenomen annelerin paylaşımlarında en çok yer verdikleri ürün/markaların; eğitim, kültür/sanat, kozmetik, küçük ev aletleri, fotoğraf stüdyosu, sağlık, bebek/çocuk ürünleri, oyuncak, işletme ve giyim kategorilerinde olduğu görülmüştür. Bu kategorilerde yer alan ürün/marka ile ilgili paylaşımların beğeni sayıları incelendiğinde ise, kozmetik sektöründe yer alan markalarla ilgili paylaşımların beğeni oranlarının yüksek olduğu anlaşılmıştır. Bunun, takipçilerin çoğunluğunun kendileri gibi kadınlardan oluşmasından kaynaklandığını söylemek mümkündür.

* Paylaşımların altında paylaşım yapılan markalara ait hashtaglerin yer almaktadır. Böylece fenomen anne takipçilerini o markaların kendi oluşturdukları sosyal medya hesaplarına yönlendirebilmektedir. $\mathrm{Bu}$ da takipçinin o markanın sosyal medya hesabındaki profilini incelemesinde ve markayla ilgili çok daha ayrıntılı bilgiye ulaşmasında etkili olabilmektedir. 
* Fenomen annelerin paylaşım yaptıkları ürün/markalar içinde en çok yorum alan markaların yer aldığı kategorilerin giyim, kırtasiye, bebek ürünleri, kozmetik, alışveriş merkezi şeklinde olduğu belirlenmiştir. Yapılan incelemede; genel olarak giyim ve bebek ürünleriyle ilgili yapılan paylaşımlarda hediye verme, çekiliş gibi etkinliklerin olduğu görülmüsşür. Bunun da takipçilerin daha fazla yorum yapmasında etkili olduğu düşünülmektedir.

Araştırmadan elde edilen sonuçlar doğrultusunda, fenomen pazarlaması açısından takipçi sayısı fazla olan bu annelerin hem sevilen hem de güven veren kişiler olması sebebiyle firma ve müşteri arasında güzel bir köprü olacağını söylemek mümkündür. Paylaşımları ilgiyle takip edilen bu kişiler, ürünlerin ya da markaların pazarlanmasında başarılı birer elçi konumundadırlar. Özellikle giyim, kozmetik ve bebek ürünlerini tanıtmak isteyen firmaların bu kişilerle bağlantı kurmasında ve işbirliği sağlamasında fayda vardır. Bu kişilerin yaptıkları paylaşımların çok beğeni alması ya da bu paylaşımlara çok fazla yorum yapılması markanın konuşulmasını sağlayabilecek, viral pazarlama kapsamında markayla ilgili içeriğin sosyal medyada virüs gibi yayılmasında etkili olabilecektir.

Gelecek çalışmalar için, fenomen annelere ya da farklı alanlarda fenomen olmuş kişilere ya da bu kişilerin yaptıkları paylaşımlara yönelik tutumların ölçülmesi ya da tek bir fenomenin seçilerek o fenomenin paylaşımlarının çeşitli açılardan analiz edilmesi ya da benzer bir çalışmanın Instagram fenomeni babalar üzerinden gerçekleştirilmesi önerilebilir. Çalışmanın sadece 14 fenomen anneyi kapsaması bu araştırmanın kısııını oluşturmaktadır. İleri çalışmalarda; araştırma kapsamında, daha fazla fenomen anne ve bu fenomen annelerin daha fazla yıl içerisindeki paylaşımları incelenebilir ve çeşitli karşılaştırmalar yapılabilir.

\section{Kaynakça}

Aslan, A. \& Ünlü, D. G. (2016). Instagram Fenomenleri ve Reklam İlişkisi: Instagram Fenomenlerinin

Gözünden Bir Değerlendirme. Maltepe Üniversitesi İletişsim Fakültesi Dergisi, 3(2): 4165. 
Baker, S. (2014). Monetizing Influencers: Diffusion of Innovations and Influencer Marketing Through

Blogger Outreach. The University of Central Florida.

Brown, D. \& Hayes, N. (2015). Influencer Marketing: Who Really Influences Your Customers?

Amsterdam, Netherland: Elsevier/Butterworth-Heinemann.

Bughin, J., Doogan, J. \& Vetvik, O. (2010). A New Way to Measure Word-of-Mouth Marketing. McKinsey \& Company, http://www.mckinsey.com/NotFound.aspx?item=\%2fbusiness\&user=extranet $\% 5 \mathrm{c}$ Anony mous\&site=website, Erişim Tarihi: 15.03.2020

Can. S. \& Koz, K. A. (2018). Sosyal Medyada Tüketici Onaylı Pazarlama: İnstagram Örneği, Anadolu

Üniversitesi İletişim Bilimleri Fakültesi Uluslar arası Hakemli Dergi, 26(3): 444-457.

De Veirman, M., Cauberghe, V., Hudders, L., \& De Pelsmacker, P. (2017). Consumers' Motivation For

Lurking and Posting in Brand Communities on Social Network Sites. In S. Rodgers \& E. Thorson (Eds.), Digital Advertising, London: Routledge.

Eroğlu Pektaş, G.Ö. \& Ormanlı, F. (2019). Yeni Ana Akım Pazarlama: Influencer Pazarlaması, 4th

International EMI Entrepreneurship \& Social Sciences Congress, 29-30 Kasım, İstanbul. Hall, J. (2016) 8 Influencer Marketing Trends That Will Lead You to Success. Forbes, 16 Oct. 2016 ,

http://www.forbes.com/sites/johnhall/2016/10/16/8-influencer-marketingtrends-that-willlead-you-tosuccess/3/\#32906324148f, Erişim Tarihi: 12.03.2020

http://www.hurriyetaile.com/fotogaleri/ebeveyn/hepsi-birer-fenomen-instagramin-populeranneleri-4308, (Erişim tarihi: 15.04.2020) 
https://onedio.com/haber/kim-bu-insanlar-neden-binlerce-takipcileri-var-paylastiklari-veyaptiklariyla-her-daim-merak-edilen-16-instagram-annesi-817697, Erişim tarihi: 15.04 .2020

Mallipeddi, R., Kumar, S., Sriskandarajah, C. \& Zhu, Y. (2018). A Framework for Analyzing Influencer

Marketing in Social Networks: Selection and Scheduling of Influencers, https://papers.ssrn.com/sol3/papers.cfm?abstract_id=3255198 Erişim Tarihi: 01.03.2020

Punch, K. (2014). Sosyal Araştırmalara Giriş, (Çev: Zeynep Akyüz, Dursun Bayrak, H. Bader Arslan),

Siyasal Kitabevi: Ankara.

Ranga, M. \& Sharma, D. (2014). Influencer Marketing-A Marketing Tool in the Age of Social Media, Abhinav International Monthly Refereed Journal of Research in Management \& Technology, 3: 16-21.

Schulten, M., Mertens, A., Horx, A. (2012). Social Branding: Strategien - Beispiele - Perspektiven, Wiesbaden: Springer Gabler.

Sevinç, S. S. (2018). Blogger, Influencer, Fenomen, Instagrammer, YouTuber, Celebrity Nedir? Ne İşe

Yarar? Nas11 İstifade Edilir? http://salihseckinsevinc.com/blogger-influencer-fenomeninstagrammer-youtuber-celebrity-nedir-ne-ise-yarar-nasil-istifade-edilir/, Erişim Tarihi: 10.03.2020.

Sudha, M. \& Sheena, K. (2017). Impact of Influencers in Consumer Decision Process: The fashion industry. SCMS Journal of Indian Management, [e-journal] 14(3), Available through: LUSEM Library, https://www.lub.lu.se/en/search-systems-andtools/lubsearch, Erişim Tarihi:10.03.2020 Tabellion, J. \& Esch, F.R. (2019). Influencer Marketing and Its Impact on the Advertised Brand, 
Advances in Advertising Research, In: Bigne E., Rosengren S. (Eds) Advances in Advertising

Research X. European Advertising Academy. Wiesbaden: Springer Gabler.

Tapinfluence. (2017). What is Influencer Marketing?

https://www.tapinfluence.com/blog-what-is-influencer-marketing/ Erişim Tarihi: 10.03 .2020

Trusov, M., Bucklin, R. E. \& Pauwels, K. (2009). Effects of Word-of-mouth Versus Traditional Marketing: Findings from an Internet Social Networking Site, Journal of Marketing, 73 (5): 90102.

Vodak, J., Novysedlak, M., Cakanova, L. \& Pekar, M. (2019). Influencer Marketing as a Phenomenon

in Reputation Management, Managing Global Transitions, 17(3): 211-220.

Wong, K. (2014). The Explosive Growth of Influencer Marketing and What it Means for You. Forbes,

http://www.forbes.com/sites/kylewong/2014/09/10/the-explosive-growth-of- influencermarketing-and-what-it-means-for-you/ , Erişim Tarihi: 12.03.2020

Yodel, G. (2017). What is Influencer Marketing?, Huffington Post, July 6, http://www.huffingtonpost.com/global-yodel/what-isinflucnermarketing_b_10778128.html

Erişim Tarihi: 10.03 .2010 